Published as: Hardiker N, Park HA. Nursing Informatics: a personal review of the past, the present and the future. Journal of Korean Society of Medical Informatics. 2005; 11 (2): 119-124.

\title{
Nursing Informatics: a personal review of the past, the present and the future
}

\author{
Nicholas Hardiker RN PhD \\ Senior Research Fellow \\ University of Salford \\ United Kingdom \\ Hyeoun-Ae Park RN PhD \\ Professor \\ College of Nursing \\ Seoul National University \\ Korea
}

Salford Health Informatics Research Environment

\begin{abstract}
There is evidence that nurses have been involved in, or have been affected by health-related computer projects since the mid-1960's. Since those early years nurses have made many significant contributions to the wider bio-health informatics agenda. This article reflects on the evolution of Nursing Informatics, from attempts to define the discipline, through the development of support systems, to the current state-of-the-science for one particular and important field of study, namely clinical terminologies. The article concludes with a call for increased professionalisation of Nursing Informatics.
\end{abstract}

\section{Introduction}

Nurses have been involved in health-related computer projects for several decades, with nursing-relevant publications dating as far back as 1965 (Sherman, 1965). Notable work was carried out throughout the 1960s and 1970s. For example, in 1975 Goodwin (now Ozbolt) and Edwards described the development and testing of a computer program to support the nursing process (Ozbolt \& Edwards,1975). To put this into historical perspective, this visionary work was carried out two years before the nursing process was formally introduced into the United Kingdom; and six years before IBM launched its first Personal Computer. Despite significant achievements in these two decades, it was not until the 1980s that Nursing Informatics truly found its feet (in Korea, articles on Nursing Informatics began to appear in the domestic literature in the early 1990s). The purpose of this article is to review the past 25 years of Nursing Informatics, to identify selected significant milestones and to reflect on the current state-of-the-science through a case study on work around nursing terminology. 
Published as: Hardiker N, Park HA. Nursing Informatics: a personal review of the past, the present and the future. Journal of Korean Society of Medical Informatics. 2005; 11 (2): 119-124.

\section{Defining Nursing Informatics}

One of the first published definitions for Nursing Informatics appeared in the proceedings of Medinfo 80, the third World Congress of Medical Informatics, which was held in Tokyo in 1980:

'...the application of computer technology to all fields of nursing -- nursing services, nurse education, and nursing research'. (p 73) (Scholes \& Barber, 1980).

Throughout the 1980s, a number of scholars reinforced this information technology-oriented view. For example, in 1985 Hannah (1985) proposed the following definition:

'The use of information technology in relation to any of the functions which are within the purview of nursing and which are carried out by nurses. Hence, any use of information technology by nurses in relation to the care of patients, or the educational preparation of individuals to practice in the discipline is considered nursing informatics.' (P. 181)

In 1989 Graves \& Corcoran (1989) took an important step by looking beyond the mere application of information technology:

"Nursing Informatics is a combination of computer science, information science and nursing science, designed to assist in the management and processing of nursing data, information and knowledge to support the practice of nursing and the delivery of nursing care." (p. 227).

With this definition, the emphasis of Nursing Informatics moved away from applying information technology within the domain of nursing, to supporting nursing through a much broader informatics. Thus there would appear to be three key features that characterize Nursing Informatics:

1. Supporting health

2. Managing data, information and knowledge that is relevant to nursing

3. Using tools or techniques from a number of academic disciplines.

These features persist in more recent attempts to define Nursing Informatics, such as the definition adopted in 1998 by the Special Interest Group on Nursing Informatics of the International Medical Informatics Association (IMIA$\mathrm{NI})$ :

'Nursing Informatics is the integration of nursing, its information, and information management with information processing and communication technology, to support the health of people world wide'.(IMIA, 2005)

\section{Supporting Nursing Informatics}

The fourth World Congress of Medical Informatics (Medinfo 83) was an important event for Nursing Informatics as it provided the venue for the first meeting of IMIA-NI. IMIA-NI was established initially as Working Group 8 of International Medical Informatics Association in order to serve the needs of people working in the field of Nursing Informatics. The need for a new Working Group had been identified in London the previous year at a conference entitled 'The Impact of Computers on Nursing'. This first 
Published as: Hardiker N, Park HA. Nursing Informatics: a personal review of the past, the present and the future. Journal of Korean Society of Medical Informatics. 2005; 11 (2): 119-124.

international conference on Nursing Informatics attracted 550 delegates impressive even by today's standards - and demonstrated a significant groundswell of interest.(Scholes et al., 2000)

The overall aim of IMIA-NI still holds today, and the original terms of reference have been expanded over the years into a number of goals. These include, to:

- foster collaboration among nurses and others who are interested in nursing informatics;

- $\quad$ explore the scope of nursing informatics and its implication for information handling activities associated with nursing care delivery, nursing administration, nursing research and nursing education, and the various relationships with other health care information systems;

- support the development of nursing informatics in the member countries;

- $\quad$ provide appropriate informatics meetings, conferences and postconferences and provide opportunities to share knowledge and research to facilitate communication of developments in the field;

- encourage the publication and dissemination of research and development materials in the field of nursing informatics;

- develop recommendations, guidelines and courses related to nursing informatics (IMIA, 2005).

The General Assembly of IMIA-NI is made up of representatives from around the world, nominated by national Nursing Informatics groups which play a more local supporting role. Examples include the British Computer Society Health Informatics (Nursing) Specialist Group and the American Medical Informatics Association Nursing Informatics Working Group. The Nursing Informatics Special Interest Group of the Korean Society for Medical Informatics was founded in 1993; it has represented Korea at the IMIA-NI General Assembly since 1995.

The Second international conference on Nursing Informatics, entitled 'Building bridges to the future', was held in Calgary, Canada in 1985. IMIA-NI assumed responsibility for organizing this conference and has continues to organize the triennial International Congress in Nursing Informatics. The next such conference (NI 2006) will be held in Seoul, Korea in 2006.

\section{'Doing' Nursing Informatics}

The topic areas to be considered at NI 2006 reflect an impressive breadth of knowledge in Nursing Informatics; indeed it would be difficult to find an area of Bio-Health Informatics that has not been influenced by Nursing Informatics. One particular area in which Nursing Informatics has made a significant contribution is in the field of clinical terminology.

A major influencing factor on terminology work in nursing was the development in the 1980's of a Nursing Minimum Data Set (NMDS) in the USA (Werley \& Lang, 1988). A NMDS is a high-level information model that provides a framework for the consistent collection of nursing-relevant data. Of course, substantial terminology work had been carried out prior to the 
Published as: Hardiker N, Park HA. Nursing Informatics: a personal review of the past, the present and the future. Journal of Korean Society of Medical Informatics. 2005; 11 (2): 119-124.

realization of the NMDS. However, work on the NMDS focused efforts and provided an impetus for the extensive development and refinement of structured terminologies for describing patient problems, nursing interventions, and nursing-sensitive patient outcomes (Johnson et al., 2000; Martin \& Scheet, 1992; McCloskey \& Bulechek, 2000; North American Nursing Diagnosis Association, 2003; Ozbolt, 1998; Saba, 2002).

The number of terminologies that support nursing practice continues to grow. In 1994, the American Nurses Association (ANA) Steering Committee on Databases to Support Clinical Nursing Practice recognized four terminologies; the ANA, through its Nursing Information and Data Set Evaluation Center, currently recognizes thirteen terminologies. There are of course many more terminologies in use by nurses across the world.

In response to this proliferation of terminologies worldwide and the increasing need to provide comparable nursing data a number of researchers in the 1990's recognized the need for a more rigorous approach to nursing terminology (Henry \& Mead, 1997; Hardiker \& Rector, 1998). Their seminal work in nursing concept representation continues to influence terminology work in nursing and beyond and has provided a significant contribution to the development of reference terminologies such as SNOMED Clinical Terms and the International Classification for Nursing Practice (ICNP), an initiative led by the International Council of Nurses (ICN) (Coenen, 2003). In order to inform and support the development and integration of a nursing reference terminology the Nursing Terminology Summit was established in 1999 as an invitational international think-tank that meets annually at Vanderbilt University, Nashville (Ozbolt et al., 2001).

This foundational work also prompted efforts in international standardization, building on previous work conducted in Europe (European Committee for Standardization, 2000). The standards initiative was jointly led by ICN and IMIA-NI (demonstrating its supporting role in Nursing Informatics), and it was conducted under the auspices of the International Organization for Standardization (ISO). The result was an international standard, 'Integration of a Reference Terminology Model for Nursing', which defines the desirable characteristics of statements that describe nursing diagnoses and nursing actions (International Organization for Standardization, 2003). The standard (ISO 18104:2003) is the first international technical standard for nursing; it is also the first international standard to come out of the terminology working group of ISO's Health Informatics technical committee (ISO/TC215). It is a significant achievement that has positioned Nursing Informatics as a major player in Bio-Health Informatics.

Korea has played an active and important role in many of these international initiatives. For example:

- Hyeoun-Ae Park was involved in the development and testing of ISO 18104:2003 and is a participant in the Nursing Terminology Summit

- Korean researchers have embraced ICNP and demonstrated its utility in nursing practice. 
Published as: Hardiker N, Park HA. Nursing Informatics: a personal review of the past, the present and the future. Journal of Korean Society of Medical Informatics. 2005; 11 (2): 119-124.

\section{Advancing Nursing Informatics}

Nursing Informatics has made significant contributions to the broader BioHealth Informatics agenda such as in Consumer Health Informatics (Brennan, 1995) and in clinical terminology work (as described previously).

Nursing Informatics continues to have a major presence. Current and recent evidence of this presence includes:

- Judy Ozbolt, who is current chair-elect for the American College of Medical Informatics

- Heimar de Fatima Marin, who presented a keynote speech at Medinfo 2004 (she was the first nurse to present a keynote at Medinfo since the inaugural meeting in 1974)

- Patti Brennan, who was recent chair of the board of the American Medical Informatics Association (five members of the present board of eighteen people have a nursing qualification)

- Anne Casey, who is leading a more general international standard effort within ISO to determine quality indicators for diverse clinical terminologies (a Nursing Task Force is currently being considered within the Health Informatics Technical Committee to ensure adequate nursing representation and input)

- Hyeoun-Ae Park, who is leading Nursing and wider Health Informatics standards work in Korea in her role as chair of the ISO/TC 215 Korean Technical Advisory Group.

There is little doubt that Nursing Informatics should be considered a discipline i.e. a field of study. There are now numerous Masters-level training programs across the world that either focus on Nursing Informatics or that include at least a large Nursing Informatics component e.g. at the University of Colorado in the USA and Seoul National University in Korea. Other Doctoral-level Nursing Informatics programs are increasing in number e.g. at the University of Maryland and the University of lowa.

More questionable is whether Nursing Informatics should be considered a profession. To draw a parallel with nursing, the professionalisation of nursing was built upon a number of key foundations including:

a) marketable specialized knowledge (affording also a degree of autonomy)

b) standards of practice (with controlled entry into the profession)

c) regulation by an occupational organization (with disciplinary powers) (Shober \& Hinchliff, 1985).

These building blocks are now in place in many countries and consequently nursing is regarded in those countries as a profession.

Nursing Informatics also comprises a unique body of knowledge that is related to, but distinct from nursing, information science, and information and communication technologies, as organizations that are seeking to recruit nursing informatics specialists across the world will testify. Standards of 
Published as: Hardiker N, Park HA. Nursing Informatics: a personal review of the past, the present and the future. Journal of Korean Society of Medical Informatics. 2005; 11 (2): 119-124.

practice and organizational regulation are less mature in Nursing Informatics. However, initiatives are underway, such as the Informatics Nurse certification by the American Nurses Association which demonstrates that those who qualify meet nationally recognized standards in Nursing Informatics; initiatives that would suggest that a move to professionalisation is inevitable.

\section{Summary}

Nursing Informatics has come a long way since its 'birth'. It is clear about its identity, it has a robust support system and an expanding marketable knowledge base, and it continues to make important contributions to the wider Bio-Health Informatics agenda. There is little doubt that Nursing Informatics has the ability to help nurses, their colleagues and, not least, their patients. It is worth acknowledging that Nursing Informatics also has the ability to harm; consistent standards of practice and organizational regulation must now be considered essential as Nursing Informatics moves towards professionalisation.

\section{References}

Brennan, PF. (1995). Characterizing the use of health care services delivered via computer networks. J Am Med Inform Assoc. 2(3): 160-168.

Coenen, A. (2003). Building a unified nursing language: The ICNP. International Nursing Review 50(2):65-66.

European Committee for Standardization. (2000). CEN ENV Health Informatics-Systems of Concepts to Support Nursing. Brussels: CEN.

Goodwin, JO and Edwards, BS. (1975). Developing a computer program to assist the nursing process: phase I - from systems analysis to an expandable program. Nursing Research. 24(4):299-305.

Graves, JR and Corcoran, S. (1989). The study of Nursing Informatics. IMAGE: Journal of nursing scholarship. 21(4): 227-231.

Hannah, K. (1985). Current trends in nursing informatics: Implications for curriculum planning. In: K. J. Hannah, E. J. Guillemin \& D. K. Conklin (Eds.). Nursing uses of computers and information science. Amsterdam: Elsevier Science Publishing, Inc., 181 - 187.

Hardiker, N. and Rector, A. (1998). Modeling nursing terminology using the GRAIL representation language. J Am Med Inform Assoc 5(1):120-128.

Henry, S.B. and Mead, C.N. (1997). Nursing classification systems: Necessary but not sufficient for representing "what nurses do" for inclusion in computer-based patient record systems. J Am Med Inform Assoc 4(3):222232.

IMIA (2005). Retrieved 15 March 2005, from the World Wide Web, http://www.imia.org/ni/index.html.

International Organization for Standardization. (2003). International Standard ISO 18104:2003 Health Informatics_Integration of a Reference Terminology Model for Nursing. Geneva, Switzerland: International Organization for Standardization. 
Published as: Hardiker N, Park HA. Nursing Informatics: a personal review of the past, the present and the future. Journal of Korean Society of Medical Informatics. 2005; 11 (2): 119-124.

Johnson, M., Maas, M., and Moorhead, S. (eds.) (2000). Nursing Outcomes Classification (NOC) (2nd ed.). St. Louis, MO: C.V. Mosby.

Martin, K.S. and Scheet, N.J. (1992). The Omaha System: Applications for community health nursing. Philadelphia, PA: W.B. Saunders.

McCloskey, J.C. and Bulechek, G.M. (2000). Nursing Interventions Classification (3rd ed.). St. Louis, MO: C.V. Mosby.

North American Nursing Diagnosis Association. (2003). NANDA Nursing Diagnoses 2003-2004: Definitions and Classification. Philadelphia, PA: North American Nursing Diagnosis Association

Ozbolt, J.G. (1998). Ozbolt's Patient Care Data Set, Version 4.0. Nashville, TN: Vanderbilt University.

Ozbolt J, Androwich I, Bakken S, Button P, Hardiker N, Mead C, Warren J, Zingo C. (2001) The Nursing Terminology Summit: Collaboration for Progress. In: Patel V, Rogers R, Haux R (eds.). Medinfo 2001. Amsterdam: IOS Press, 236-240.

Saba, V. (2002). Retrieved March 14, 2002, from the World Wide Web, http://www.sabacare.com

Schober, J. E. and Hinchliff, S. M. (1995). Towards advanced nursing practice: key concepts for health care. London: Arnold.

Scholes, M. and Barber, B. (1980). Towards nursing informatics. In: Lindberg, D \& Kaihara, S (eds.) MEDINFO 80. Proceedings of the 3rd World Congress on Medical Informatics. Amsterdam: North-Holland, 70-73.

Scholes, M, Tallberg, M. and Pluyter-Wenting, E. (2000). International nursing informatics: a history of the first forty years 1960-2000. Swindon: The British Computer Society.

Sherman R. (1965). Computer system clears up errors, lets nurses get back to nursing. Hospital Topics. 43(10):44-6. 